\title{
Vetting and safeguarding rules
}

\section{James Goldman}

Associate Director of Advisory Services

$\mathrm{F}$ rom time to time, we hear about cases where someone has abused a large number of vulnerable people. These cases usually occur because people missed opportunities to stop them.

Very occasionally, members of the dental team are struck off the GDC register for deliberately harming patients in one way or another. Vetting of dental staff likely plays a role in ensuring that this stays no more than very occasional. It is important to ensure that those who pose a risk to dental practice patients are prevented from working in the dental practice.

But vetting is a small aspect of safeguarding. The bigger picture, by far, is the role that members of the dental team play to spot when patients may be abused and take action to help.

Abuse comes in many shapes and forms. It could be failing to bring a child to the dentist for routine treatment, sexual abuse, and everything in between. Because it is not

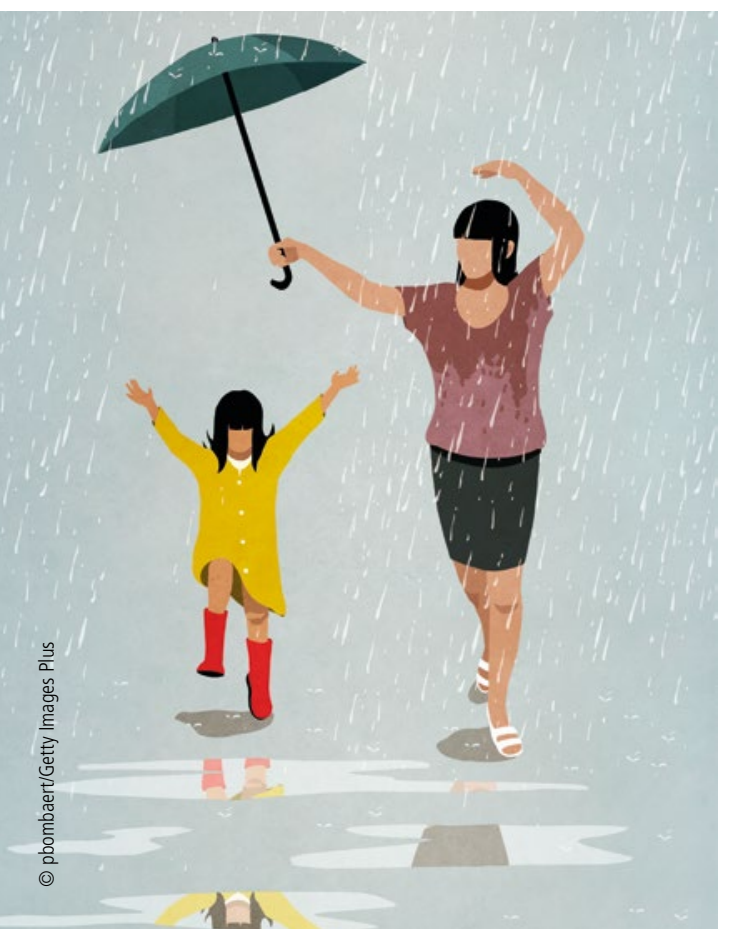

something that arises every day, or even every year, members of the dental team will not be used to reacting in the correct way.

In Adam Kay's book about his time working in hospitals, 'This is going to hurt,' he referred to the fact that in hospitals there are often little stickers in the women's toilets that female patients can put on a sample or on their notes to indicate to a doctor that they are suffering abuse and want to speak to someone. The only time Adam Kay says he saw one of these stickers, he prised the female patient and her two-year-old child away from her husband, only to be told that the stickers were the efforts of the child to be artistic.

But we have had a member tell us about a teenager with signs of bulimia who complained of being bullied. And we have been told of issues by members who have seen things that can amount to abuse, including failures to bring children to appointments.

\section{Rules on vetting}

Practices must have obtained criminal record disclosures and checks on barred lists for all dentists and DCPs working at the practice and encourage applicants to join the update system.

Criminal record checks are only valid at the point of disclosure and have no expiry date. It is up to you to decide when a new check is needed but we recommend at regular intervals (every three years, for example) or if someone has a break in service of over three months or there are concerns about their conduct. You should check that all new recruits who are directly involved with patient care are not barred from working with children or adults at risk.

For new members of the dental team, whether employed or self-employed, you should also check that they are entitled to work in the UK, are registered with the GDC (where relevant), have undergone relevant health screening and immunisation and are safe to work with vulnerable groups.

\section{Safeguarding in the practice}

There should be a lead person at the practice to take leadership responsibility for the practice's safeguarding arrangements. That person will need the required training to understand how to take leadership and what arrangements need to be made.

The lead will also need to be able to support other members of the dental team. They ensure they and the dental team know the local safeguarding people to contact if, say, a child protection issue arises.

There should be a clear whistleblowing procedure to ensure staff concerns can be raised and addressed.

\section{Training on Safeguarding}

The duties and procedures to protect children and at-risk adults from abuse and neglect must be understood by all members of the team. Practices should ensure there is formal training on these issues as part of the induction process for all new staff.

Formal training provides the opportunity to discuss case scenarios, hear other views and consider the appropriate actions to take in those scenarios. New staff need to know who leads safeguarding at the practice and who to go to if there are problems.

In England and Wales, there should be at least level 1 training for all staff, and level 2 training for all clinical staff (and nonclinical staff in Wales). Staff should undertake refresher courses every year, with full training repeated every three years.

In Scotland, practices are required to follow the National Framework for Child Protection learning and development 2012, which identifies three groups, each requiring different competencies and knowledge.

For Northern Ireland, practices are required to comply with the training competencies described in Co-operating to safeguard children 2003 published by Department of Health, Social Services and Public Safety.

Practices should hold staff training sessions and use a either a safeguarding case (redacted and anonymised) that has happened in the practice, or a created scenario, and make sure all staff can role play in the scenario and know what to do. This will help keep safeguarding at the forefront of everyone's mind.

With the right vetting and the right training, all members of the dental team should be ready and able to connect someone who needs it with the right help and, maybe, make a huge difference to someone's life. https://doi.org/10.1038/s41404-020-0452-2 